Reactor and Nuclear Systems Division

\title{
IMPROVEMENTS IN ORIGEN RESOURCE READERS
}

\author{
Shane W. D. Hart \\ Andrew M. Holcomb \\ William A. Wieselquist \\ Dorothea Wiarda
}
Oak Ridge National Laboratory
P.O. Box 2008
Bldg. 5700, MS-6170
Oak Ridge, TN 36831-6170

Date Published: March 31, 2018

\begin{abstract}
Prepared for the
Nuclear Energy Advanced Modeling and Simulation Project under the Department of Energy
\end{abstract}

Approved for public release. Distribution is unlimited.

Prepared by OAK RIDGE NATIONAL LABORATORY

Oak Ridge, TN 37831-6283

managed by

UT-BATTELLE, LLC

for the

US DEPARTMENT OF ENERGY

under contract DE-AC05-00OR22725 


\section{DOCUMENT AVAILABILITY}

Reports produced after January 1, 1996, are generally available free via US Department of Energy (DOE) SciTech Connect.

Website http://www.osti.gov/scitech/

Reports produced before January 1, 1996 may be purchased by members of the public from the following source:

National Technical Information Service

5285 Port Royal Road

Springfield, VA 22161

Telephone 703-605-6000 (1-800-553-6847)

TDD 703-487-4639

Fax 703-605-6900

E-mail info@ ntis.gov

Website http://www.ntis.gov/help/ordermethods.aspx RData Exchange representatives, and International Nuclear Information System representatives from the following source:

Office of Scientific and Technical Information

PO Box 62

Oak Ridge, TN 37831

Telephone 865-576-8401

Fax 865-576-5728

E-mail reports@osti.gov

Website

This report was prepared as an account of work sponsored by an agency of the United States Government. Neither the United States Government nor any agency thereof, nor any of their employees, makes any warranty, express or implied, or assumes any legal liability or responsibility for the accuracy, completeness, or usefulness of any information, apparatus, product, or process disclosed, or represents that its use would not infringe privately owned rights. Reference herein to any specific commercial product, process, or service by trade name, trademark, manufacturer, or otherwise, does not necessarily constitute or imply its endorsement, recommendation, or favoring by the United States Government or any agency thereof. The views and opinions of authors expressed herein do not necessarily state or reflect those of the United States Government or any agency thereof. 


\section{Contents}

1 Introduction $\quad 1$

2 Legacy Resource File Creation $\quad 1$

3 Current Resource Development $\quad 2$

3.1 Yield Resource . . . . . . . . . . . . . . . . . . . 3

3.2 Decay Resource . . . . . . . . . . . . . . . . . . 3

4 ENDF Resource Readers $\quad 4$

4.1 Yield Resource . . . . . . . . . . . . . . . . . . . . . . 4

4.2 Decay Resource . . . . . . . . . . . . . . . . . . . . . . . 4

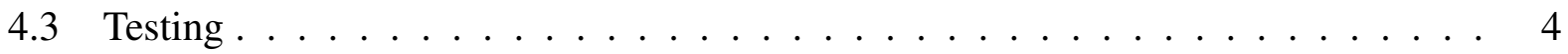

4.3.1 Card Image versus ENDF-VII.1 . . . . . . . . . . . . . 4

4.3.2 ENDF/B-VII.1 versus ENDF/B-VIII.0 . . . . . . . . . . . 5

$\begin{array}{lll}5 & \text { Conclusions and Future Work } & 7\end{array}$ 



\section{LIST OF FIGURES}

1 ORIGEN legacy resource file use. . . . . . . . . . . . . . . . 2

2 ORIGEN new resource file use. . . . . . . . . . . . . . . . . 3

3 Decay chains around ${ }^{192 m}$ Ir. . . . . . . . . . . . . . 8 



\section{LIST OF TABLES}

1 Decay results for $1 \mathrm{~mol}$ of ${ }^{252} \mathrm{Cf}$ after 1 year of decay $\ldots \ldots \ldots$

2 Decay results for $1 \mathrm{~mol}$ of ${ }^{95} \mathrm{Y}$ after 30 days of decay $\ldots \ldots \ldots$

3 Specific activity for fission products of ${ }^{235} \mathrm{U}$ burst fission $(\mathrm{Bq} / \mathrm{g}) \ldots \ldots$

4 Specific activity for fission products of ${ }^{239} \mathrm{Pu}$ burst fission . . . . . . . . . . 6

$5 \quad$ ENDF/B-VII.1 and ENDF/B-VIII.0 transition differences . . . . . . . . . . 7 



\section{INTRODUCTION}

As part of the effort to modernize the ORIGEN depletion code [1], various "resources" have been created to store the fundamental nuclear data required for ORIGEN calculations, such as fission yields, decay data, and cross sections. The resources provide a convenient interface to load the same data from various file formats. Resources can be used directly in unit conversions (e.g., the decay resource can be used to convert atoms to activity) and are the fundamental input used to create an ORIGEN library, which is a fixed data collection of a specific set of nuclides and transitions. This report focuses on the extension of the yield resource and the decay resource, which allow ENDF-formatted nuclear data files [2] to be read directly.

The yield resource contains information about the various daughter fission products from neutroninduced fission. This yield information includes a list of fissionable nuclides, and for each fissionable nuclide, a list of fractional yields for each daughter fission product, potentially as a function of incident neutron energy.

The decay resource contains information about the radioactive decay properties of a large set of nuclides. This decay information includes

- the decay constant/half-life for each nuclide,

- a branch ratio for each (potentially compound) decay mode $\left(\beta^{-}, \beta^{+}, n, \alpha\right.$, etc.), and

- an effective yield for each daughter isomeric state if the decay mode has more than one.

Each resource has the ability to read and write various formats to disk. Previously these were limited to so-called "card image" formats created by utilities in the AMPX package [3], which would themselves read ENDF data and create a resource file using a predefined list of ORIGEN nuclides. Extending the ORIGEN resources to read ENDF data files reduces the total processing stages and avoids making decisions about the relevant nuclides in a calculation earlier than necessary. Additionally, extending the resources allows for better testing and quality control when the capability to create ORIGEN resource files is within ORIGEN (where there is access to solvers and models for testing) instead of an external code package.

\section{Legacy Resource file Creation}

The general flow of the previous process for resource creation is given in Figure 1. As can be seen from the figure, AMPX reading functions are used to directly populate fixed-format ASCII text files. These text files (referred to as the card image-formatted files) are rigid in their content and new types of data cannot be added or removed easily. Additionally, as shown in the figure, it requires declaration of the nuclides and sublibraries (a category for a nuclide) during the resource creation stage. 


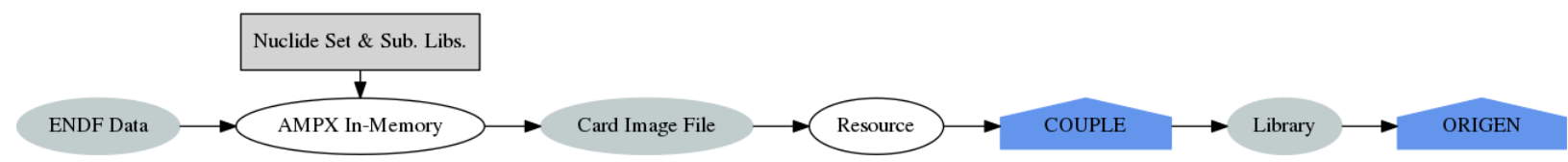

Figure 1: ORIGEN legacy resource file use.

As an example, consider the decay mode $\beta^{+}$followed by spontaneous fission, denoted $\beta^{+}$, s. $f$. The decay resource card image file was restricted to eight decay modes that were based on the available data in ENDF/B at the time the format was developed, which did not include $\beta^{+}, s . f$. Additionally, to create the card image decay resource file, a user must select the complete set of nuclides (sublibrary, ordering, allowed decays). Although the format is documented in manuals, it was not easy for users to use AMPX to create their own card image files when they wanted to change or test changes or update to a new version of the data. Recently, components of the AMPX code package have been modernized, and the code base was subjected to a software quality assurance plan. However, the ORIGEN resource writing process did not receive much attention. Modernization efforts mainly focused on cross-section processing, and the process to create ORIGEN resources was not described in any documentation.

Once the card image files have been created, they can be read by the respective resource readers in ORIGEN.

\section{Current Resource Development}

In addition to the yield and decay resources described previously, there are also resources for activation cross section data, gamma emission data, and nuclide data (mass, abundance, etc.). The vision for these resources is to provide an accessible mirror of the fundamental data, without implying specific nuclide sets or transitions that will be used in a calculation, as shown in Figure 2 where the resources and user data are processed by the COUPLE code to create ORIGEN libraries, which are actually used in calculations. These resources also have the ability to read and write data to and from disk in various formats. Depending on the data contained by the resource, these formats include JSON, ASCII text files, and some binary data formats.

Some of the main drivers to add ENDF readers to the current resources are

- reducing the requirements of the ORIGEN user (i.e., knowing how to use AMPX to create card image files from ENDF data),

- allowing users to load different ENDF-formatted data (All major evaluated nuclear data libraries are provided in ENDF format including ENDF/B, JEFF, TENDL, and JENDL.),

- modifying the ENDF data or testing new data,

- moving toward a more cohesive ORIGEN package without external utility dependencies, and 
- removing limitations imposed by the card image format itself.

In the longer term, it will hopefully be possible to entirely remove "preprocessing" codes such as COUPLE and have ORIGEN read the data files itself as needed. The current version of COUPLE has been updated to use the various resource classes to create ORIGEN libraries. This contrasts with the legacy version of COUPLE that only read and manipulated the decay and yield data directly from the card image files.

\subsection{YieLd RESOURCE}

As mentioned previously, the yield resource contains information on the neutron-induced yields of the fission reactions. Of particular importance are the yield fractions of the various daughter products. Currently ORIGEN ships with the card image format of the yield resource that has been created using AMPX tools. With the ENDF reader in the yield resource, users can use the yield resource to read the ENDF data directly. The simplified process is shown in Figure 2.

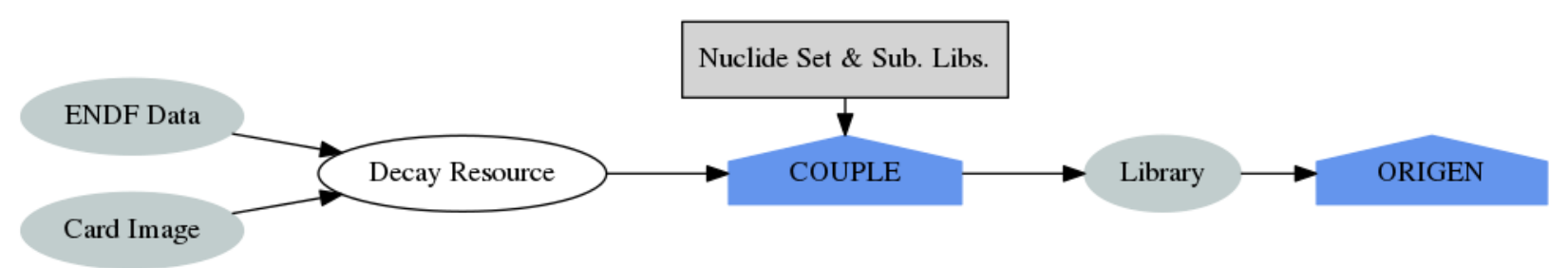

Figure 2: ORIGEN new resource file use.

\subsection{DeCay Resource}

The decay resource contains information on the decay modes of various radioactive isotopes. It can be used to easily create a decay-only library that would be used for decay calculations (no activation by flux). Like the yield resource, ORIGEN ships with the ASCII text card image file. In addition, this card image file has been processed into a binary ORIGEN decay library. Users can use COUPLE to recreate this binary decay library file, or make changes to the card image file and create a different binary file. This process is not intuitive for many users, and it may be difficult to update or change the decay data. By allowing the decay resource to read the ENDF decay data, it is hoped that it will be easier for users to update and manipulate this data. 


\section{ENDF RESOURCE READERS}

\subsection{YIELD RESOURCE}

Adding an ENDF reader to the ORIGEN yield resource allows the new ENDF/B-VIII.0 data to be easily compared to the last release, ENDF/B-VII.1. Every resource has several ways to export the data, either to a file or various printouts to the screen, which allows easy scrutiny and comparison. The change log [2] for the ENDF fission yield data specifies that nothing has been added and only the headers and dates have been changed.

\subsection{DECAY RESOURCE}

Like the yield resource mentioned above, the addition of an ENDF reader into the ORIGEN decay resource allows users to bypass the card image format and all of the restrictions that come with it. Because the decay resource can now read using both the card image and ENDF formats, the in-memory representation of the decay data can be directly compared to ORIGEN decay tests.

\subsection{Testing}

Testing of both the card image versus the ENDF/B-VII.1 data and the two ENDF/B versions was conducted. Several decay cases and burst fission cases were utilized and are described below.

\subsubsection{Card Image versus ENDF-VII.1}

By comparing a decay resource printout of a decay resource object created by the card image file with one created by the ENDF/B-VII.1 data, differences in the data can be quickly observed. One large difference is that the card image-created resource has 1,674 parent nuclides, whereas the ENDF-created resource has 3,820 parent nuclides. The nuclides actually used in creation of the binary ORIGEN library are set by COUPLE to be a subset of all nuclides that are available, so only part of the 3,820 parent nuclide set will be used. However, a substantial number of transitions will be added, and others will be slightly different because of the card image format limitations. The binary library created using the card image has 2,925 transitions, whereas the binary library created using the ENDF file has 3,142 transitions.

To test the impact of the different decay resource readers, a couple of test cases were designed and implemented. The first set of cases decay $1 \mathrm{~mol}$ of various radioactive nuclides. Californium-252 was chosen as one test isotope because it was used in a current regression test case in ORIGEN. Yttrium-95 was chosen as another decay example because transitions relating to it were explicitly added in the ENDF-VIII.0 change log [2], and it is currently included in the set of default nuclides in ORIGEN. The results comparing the decay cases are provided in Tables 1 and 2. 
Table 1: Decay results for $1 \mathrm{~mol}$ of ${ }^{252} \mathrm{Cf}$ after 1 year of decay

\begin{tabular}{c|c|c|c|c} 
& $\begin{array}{c}\text { Card image } \\
(\mathrm{g})\end{array}$ & $\begin{array}{c}\text { ENDF-VII.I } \\
(\mathrm{g})\end{array}$ & $\begin{array}{c}\text { ENDF-VIII.0 } \\
(\mathrm{g})\end{array}$ & $\begin{array}{c}\text { Difference } \\
(\%)\end{array}$ \\
\hline${ }^{4} \mathrm{He}$ & $8.9426 \mathrm{E}-01$ & $8.9423 \mathrm{E}-01$ & $8.9423 \mathrm{E}-01$ & -0.00335 \\
${ }^{236} \mathrm{U}$ & $3.8950 \mathrm{E}-18$ & $3.8947 \mathrm{E}-18$ & $3.8947 \mathrm{E}-18$ & -0.00770 \\
${ }^{240} \mathrm{U}$ & $1.0116 \mathrm{E}-15$ & $1.0115 \mathrm{E}-15$ & $1.0115 \mathrm{E}-15$ & -0.00989 \\
${ }^{240 m} \mathrm{~Np}$ & $8.6336 \mathrm{E}-18$ & $8.6327 \mathrm{E}-18$ & $8.6327 \mathrm{E}-18$ & -0.01042 \\
${ }^{240 m} \mathrm{~Np}$ & $8.8823 \mathrm{E}-20$ & $8.8814 \mathrm{E}-20$ & $8.8814 \mathrm{E}-20$ & -0.01013 \\
${ }^{240} \mathrm{Pu}$ & $1.4807 \mathrm{E}-13$ & $1.4806 \mathrm{E}-13$ & $1.4806 \mathrm{E}-13$ & -0.00675 \\
${ }^{244} \mathrm{Pu}$ & $5.1920 \mathrm{E}-05$ & $5.1918 \mathrm{E}-05$ & $5.1918 \mathrm{E}-05$ & -0.00385 \\
${ }^{248} \mathrm{Cm}$ & $5.5424 \mathrm{E}+01$ & $5.5422 \mathrm{E}+01$ & $5.5422 \mathrm{E}+01$ & -0.00361 \\
${ }^{252} \mathrm{Cf}$ & $1.9397 \mathrm{E}+02$ & $1.9397 \mathrm{E}+02$ & $1.9397 \mathrm{E}+02$ & 0.00000
\end{tabular}

Table 2: Decay results for 1 mol of ${ }^{95} \mathrm{Y}$ after 30 days of decay

\begin{tabular}{c|c|c|c|c} 
& $\begin{array}{c}\text { Card image } \\
(\mathrm{g})\end{array}$ & $\begin{array}{c}\text { ENDF-VII.I } \\
(\mathrm{g})\end{array}$ & $\begin{array}{c}\text { ENDF-VIII.0 } \\
(\mathrm{g})\end{array}$ & $\begin{array}{c}\text { Difference } \\
(\%)\end{array}$ \\
\hline${ }^{95} \mathrm{Y}$ & $0.0000 \mathrm{E}+00$ & $0.0000 \mathrm{E}+00$ & $0.0000 \mathrm{E}+00$ & - \\
${ }^{95} \mathrm{Zr}$ & $6.8598 \mathrm{E}+01$ & $6.8598 \mathrm{E}+01$ & $6.8598 \mathrm{E}+01$ & 0.00000 \\
${ }^{95} \mathrm{Nb}$ & $1.9484 \mathrm{E}+01$ & $1.9484 \mathrm{E}+01$ & $1.9484 \mathrm{E}+01$ & 0.00000 \\
${ }^{95 m} \mathrm{Nb}$ & $4.4061 \mathrm{E}-02$ & $4.4062 \mathrm{E}-02$ & $4.4062 \mathrm{E}-02$ & 0.00227 \\
${ }^{95} \mathrm{Mo}$ & $6.7810 \mathrm{E}+00$ & $6.7809 \mathrm{E}+00$ & $6.7809 \mathrm{E}+00$ & -0.00147
\end{tabular}

There are slight differences between the card image and ENDF results. The likely cause of these differences is the extra transitions that are present when the ENDF file is used directly. As the tables show, the masses of the reported nuclides are slightly lower than the card image data. This is consistent with additional transitions that are not being displayed because they are below the mass cutoff.

The fission burst test from the previous section can also be used. This will create many more radioactive nuclides than the simple decay test above and will showcase differences in the decay libraries created with the card image and ENDF-created resources. Because fission creates many different fission products, it is difficult to list them all concisely. In fact, all of the concentrations of the fission products fall below the cutoff for output listing in the ORIGEN text output file. The state set file, however, does contain all fission products, so an average of the differences can be calculated. Tables 3 and 4 show the specific activities for all fission products for burst fission in both ${ }^{235} \mathrm{U}$ and ${ }^{239} \mathrm{Pu}$.

\subsubsection{ENDF/B-VII.1 versus ENDF/B-VIII.0}

Recently the National Nuclear Data Center released version 8.0 of the ENDF/B data library. This includes a new version of the decay sublibrary. Using the decay resource ENDF reader allows the 
Table 3: Specific activity for fission products of ${ }^{235} \mathrm{U}$ burst fission $(\mathrm{Bq} / \mathrm{g})$

\begin{tabular}{c|c|c|c|c|c|c} 
& \multicolumn{7}{c}{ Time [s] } \\
& 0.001 & 1 & 10 & 100 & $1 \mathrm{E} 5$ & $1 \mathrm{E} 8$ \\
\hline Card image & $9.214 \mathrm{E}+20$ & $5.339 \mathrm{E}+20$ & $1.173 \mathrm{E}+20$ & $1.146 \mathrm{E}+19$ & $7.496 \mathrm{E}+15$ & $1.170 \mathrm{E}+12$ \\
& & & & & \\
ENDF/B-VII.1 & $9.214 \mathrm{E}+20$ & $5.339 \mathrm{E}+20$ & $1.173 \mathrm{E}+20$ & $1.146 \mathrm{E}+19$ & $7.496 \mathrm{E}+15$ & $1.170 \mathrm{E}+12$ \\
(vs. CI [\%]) & $(0.00)$ & $(0.00)$ & $(0.00)$ & $(0.00)$ & $(0.00)$ & $(0.00)$ \\
& & & & & \\
ENDF/B-VIII.0 & $9.214 \mathrm{E}+20$ & $5.339 \mathrm{E}+20$ & $1.173 \mathrm{E}+20$ & $1.143 \mathrm{E}+19$ & $7.511 \mathrm{E}+15$ & $1.169 \mathrm{E}+12$ \\
$($ vs. CI [\%] & $(0.00)$ & $(0.00)$ & $(-0.03)$ & $(-0.18)$ & $(0.20)$ & $(-0.07)$
\end{tabular}

Table 4: Specific activity for fission products of ${ }^{239} \mathrm{Pu}$ burst fission

\begin{tabular}{c|c|c|c|c|c|c} 
& \multicolumn{9}{|c}{ Time [s] } \\
& 0.001 & 1 & 10 & 100 & $1 \mathrm{E} 5$ & $1 \mathrm{E} 8$ \\
\hline Card image & $5.694 \mathrm{E}+20$ & $3.658 \mathrm{E}+20$ & $9.1734 \mathrm{E}+19$ & $1.100 \mathrm{E}+19$ & $7.362 \mathrm{E}+15$ & $1.397 \mathrm{E}+12$ \\
& & & & & \\
ENDF/B-VII.1 & $5.694 \mathrm{E}+20$ & $3.658 \mathrm{E}+20$ & $9.1735 \mathrm{E}+19$ & $1.100 \mathrm{E}+19$ & $7.362 \mathrm{E}+15$ & $1.397 \mathrm{E}+12$ \\
$($ vs. CI [\%]) & $(0.00)$ & $(0.00)$ & $(0.00)$ & $(0.00)$ & $(0.00)$ & $(0.00)$ \\
& & & & & & \\
ENDF/B-VIII.0 & $5.694 \mathrm{E}+20$ & $3.658 \mathrm{E}+20$ & $9.171 \mathrm{E}+19$ & $1.110 \mathrm{E}+19$ & $7.372 \mathrm{E}+15$ & $1.397 \mathrm{E}+12$ \\
$($ vs. CI [\%]) & $(0.00)$ & $(0.00)$ & $(-0.03)$ & $(-0.08)$ & $(0.13)$ & $(-0.02)$
\end{tabular}

results of the two versions of the decay data to be quickly and easily compared. The change log notes that several radioactive nuclides have decay modes added, and the hope is to see if these added transitions influence the results significantly.

For the simple decay cases described in Section 4.3.1, there does not appear to be any effect from the new ENDF/B library. It is probable that none of the decay paths from ${ }^{252} \mathrm{Cf}$ are changed by the library revision. For ${ }^{95} \mathrm{Y}$, it is also probable that the decay paths or transitions added are not in the ORIGEN default nuclide set and therefore do not affect the results of the decay calculation.

For the burst fission case, the vast majority of the nuclides have no difference in concentration across all of time steps. The biggest difference (1.01\%) occurs for the materials ${ }^{85 m} \mathrm{Kr}$ and ${ }^{85} \mathrm{Kr}$. This is consistent with the increase in transitions around that area documented in the ENDF-VIII.0 change log and in the transition differences shown in Table 5.

The binary libraries created by COUPLE can be examined to see what new or different transitions there are between the two versions of ENDF/B. A list of all of the new or different transitions in the ORIGEN binary decay library is given in Table 5. Note that there are other transitions that change between the ENDF/B versions, but most of them are filtered out by the default ORIGEN nuclide set. ORIGEN utilities have the ability to create a decay chart of the entire decay resource. Iridium-192m decay chain details for both the ORIGEN 6.2 nuclide set and the full nuclide set are provided in Figures $3 a$ and $3 b$. 
Table 5: ENDF/B-VII.1 and ENDF/B-VIII.0 transition differences

\begin{tabular}{c|c|c|c|c} 
Parent & Daughter & ENDF/B-VII.1 & ENDF/B-VIII.0 & $\begin{array}{c}\text { Difference } \\
(\%)\end{array}$ \\
\hline${ }^{82} \mathrm{Ge}$ & ${ }^{82} \mathrm{As}$ & $1.52007 \mathrm{E}-01$ & $1.52341 \mathrm{E}-01$ & $2.2 \mathrm{E}-01$ \\
${ }^{83} \mathrm{Ge}$ & ${ }^{82} \mathrm{As}$ & $4.24320 \mathrm{E}-04$ & $0.00000 \mathrm{E}+00$ & - \\
${ }^{83} \mathrm{Ge}$ & ${ }^{83} \mathrm{As}$ & $3.74251 \mathrm{E}-01$ & $3.74676 \mathrm{E}-01$ & $1.1 \mathrm{E}-01$ \\
${ }^{86} \mathrm{As}$ & ${ }^{85} \mathrm{Se}$ & $9.15792 \mathrm{E}-02$ & $2.60390 \mathrm{E}-01$ & $1.8 \mathrm{E}+02$ \\
${ }^{86} \mathrm{As}$ & ${ }^{85} \mathrm{Se}$ & $6.41908 \mathrm{E}-01$ & $4.73098 \mathrm{E}-01$ & $2.6 \mathrm{E}+01$ \\
${ }^{91} \mathrm{Br}$ & ${ }^{90} \mathrm{Kr}$ & $2.56248 \mathrm{E}-01$ & $0.00000 \mathrm{E}+00$ & - \\
${ }^{91} \mathrm{Br}$ & ${ }^{91} \mathrm{Kr}$ & $1.02499 \mathrm{E}+00$ & $1.28124 \mathrm{E}+00$ & $2.5 \mathrm{E}+01$ \\
${ }^{90} \mathrm{Kr}$ & ${ }^{90} \mathrm{Rb}$ & $2.78932 \mathrm{E}-03$ & $1.86572 \mathrm{E}-02$ & $5.7 \mathrm{E}+02$ \\
${ }^{98 m} \mathrm{Y}$ & ${ }^{97} \mathrm{Zr}$ & $1.14716 \mathrm{E}-03$ & $1.17835 \mathrm{E}-02$ & $9.3 \mathrm{E}+02$ \\
${ }^{98 m} \mathrm{Y}$ & ${ }^{98} \mathrm{Zr}$ & $3.45428 \mathrm{E}-01$ & $3.34791 \mathrm{E}-01$ & $3.1 \mathrm{E}+00$ \\
${ }^{90} \mathrm{Kr}$ & ${ }^{90 m} \mathrm{Rb}$ & $0.00000 \mathrm{E}+00$ & $2.78932 \mathrm{E}-03$ & -
\end{tabular}

\section{CONCLUSIONS AND FUtURE WORK}

With the addition of ENDF readers for the yield and decay resources, ORIGEN users can now quickly and easily create ORIGEN libraries from various evaluated nuclear data sources. Testing was performed using new ENDF/B-VIII data, but only the decay data has been updated from the previous ENDF/B-VII.1. In addition to user convenience, reading directly from ENDF-formatted data also allows ORIGEN developers and nuclear data evaluators a much more straightforward way to test the effect of data changes in actual calculations.

Testing will continue and feedback will be provided to ENDF/B-VIII evaluators regarding data shortcomings. Future work will include capabilities for nuclide selection and decay chain truncation options for creating custom ORIGEN libraries from the general resources. 


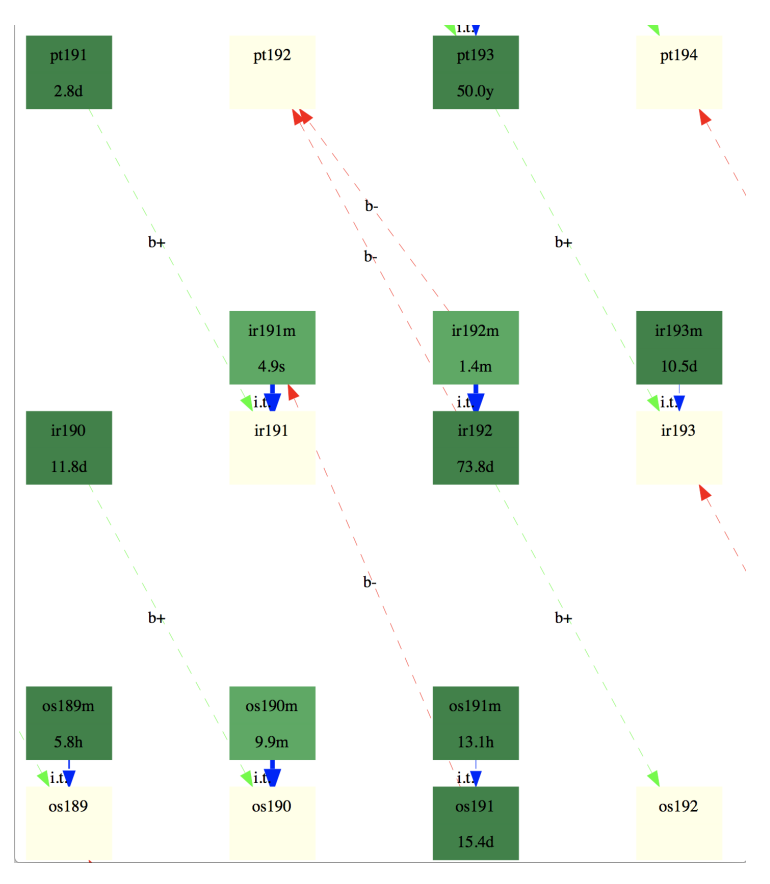

(a) ORIGEN 6.2 nuclide set

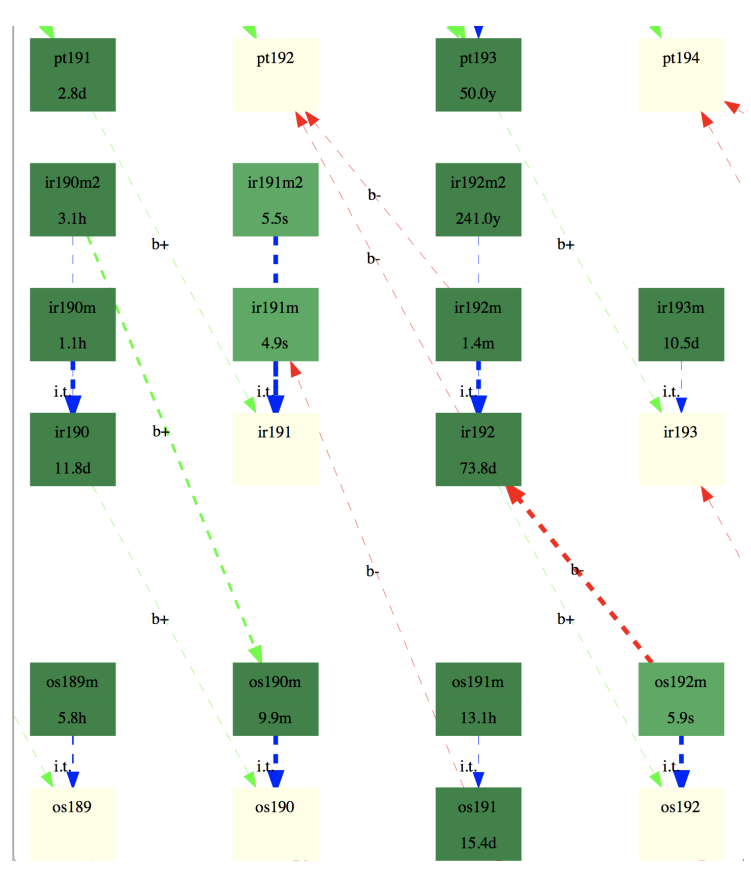

(b) Full nuclide set

Figure 3: Decay chains around ${ }^{192 m}$ Ir.

\section{REFERENCES}

[1] B. T. Rearden and M. A. Jessee. SCALE Code System, Version 6.2.1. Technical Report ORNL/TM-2005/39, Oak Ridge National Laboratory, Oak Ridge, TN (2016).

[2] D. A. Brown, M. B. Chadwick, R. Capote, et al. "ENDF/B-VIII.0: The 8th Major Release of the Nuclear Reaction Data Library with CIELO-project Cross Sections, New Standards and Thermal Scattering Data." Nuclear Data Sheets, 148:1-142 (2018). doi:https://doi.org/ 10.1016/j.nds.2018.02.001. URL https://www. sciencedirect.com/science/article/ pii/S0090375218300206.

[3] D. Wiarda, M. E. Dunn, N. M. Greene, C. Celik, et al. AMPX-6: A Modular Code System Processing ENDF/B. Technical Report ORNL/TM-2016/43, Oak Ridge National Laboratory, Oak Ridge, TN (2016). 